\title{
KOMPATIBILITAS JAMUR ENTOMOPATOGEN Beauveria bassiana Vuill. DAN PESTISIDA NABATI EKSTRAK DAUN BABADOTAN UNTUK MENGENDALIKAN HAMA KEPIK HIJAU DI LABORATORIUM
}

\author{
Susi Susanti, Lestari Wibowo \& Indriyati \\ Jurusan Agroteknologi, Fakultas Pertanian Universitas Lampung \\ Jl. Prof. Soemantri Brodjonegoro, No. 1, Bandar Lampung 35145 \\ Email: susantisusi1192@gmail.com
}

\begin{abstract}
ABSTRAK
Kompatibilitas jamur entomopatogen Beauveria bassiana Vuill. dan pestisida nabati ekstrak daun Ageratum conyzoides untuk mengendalikan hama Nezara viridula. Hama $N$. viridula merupakan hama penting yang menyerang tanaman kedelai, kacang panjang, dan padi. Hama ini dapat dikendalikan dengan menggunakan agensia hayati jamur B. bassiana, yang berfungsi sebagai bioinsektisida. Selain jamur entomopatogen, bahan aktif lainnya yang dapat digunakan sebagai bioinsektisida adalah ekstrak tumbuhan seperti ekstrak daun A. conyzoides. Penelitian ini bertujuan untuk mengetahui pengaruh kompatibilitas jamur entomopatogen $B$. bassiana dan pestisida nabati ekstrak daun A. conyzoides terhadap nimfa instar 4 atau 5 N. viridula. Rancangan percobaan yang digunakan untuk menguji daya kecambah, pertumbuhan koloni, dan sporulasi adalah acak lengkap (RAL) dengan 4 ulangan, sedangkan untuk aplikasi kompatibilitas jamur entomopatogen dengan ekstrak daun A. conyzoides menggukan rancangan acak kelompok (RAK) dengan 3 ulangan. Hasil penelitian menunjukkan bahwa persentase mortalitas $N$. viridula pada aplikasi tunggal $A$. conyzoides sebesar $91 \%$, aplikasi tunggal B. bassiana $73 \%$, aplikasi B. bassiana dicampur $1 \mathrm{ml}$ A. conyzoides sebesar $47 \%$, aplikasi B. bassiana dicampur $2 \mathrm{ml}$ A. conyzoides sebesar $64 \%$, aplikasi B. bassiana dicampur $3 \mathrm{ml}$ A. conyzoides sebesar $60 \%$ dan kontrol $0 \%$. Berdasarkan hasil penelitian tersebut dapat disimpulkan bahwa jamur entomopatogen $B$. bassiana dengan ekstrak daun $A$. conyzoides tidak kompatibel.
\end{abstract}

Kata kunci: Beauveria bassiana, ekstrak daun Ageratum conyzoides, kompatibilitas, Nezara viridula.

\section{PENDAHULUAN}

Kepik hijau (Nezara viridula L.) merupakan salah satu hama penting pengisap polong pada pertanaman kedelai, padi, dan kacang panjang. Hama kepik hijau termasuk dalam famili Pentatomidae (ordo Hemiptera) yang bersifat polifagus dan menyebabkan terhambatnya pertumbuhan tanaman dan daya kecambah benih. Hama ini dapat menurunkan hasil panen baik secara kuantitas maupun kualitas (Prayogo, 2012).

Penurunan hasil panen dapat terjadi karena penggunaan insektisida kimia yang digunakan secara terus menerus, sehingga hama kebal terhadap insektsida kimia tersebut dan berkembang pesat (Tillman, 2006 dalam Prayogo, 2012). Selain itu, dapat terjadi kasus resurjensi hama akibat penggunaan insektisida kimia yang berlebihan menyebabkan musuh alami dari hama tersebut punah dan perkembangan hama tersebut semakin meningkat (Prayogo, 2012). Resurjensi hama kepik hijau dapat dikendalikan dengan menggunakan agensia hayati seperti jamur $B$. bassiana. Penggunaan jamur B. bassiana untuk mengendalikan hama $N$. viridula telah dilakukan oleh Indriyati (2009), bahwa jamur $B$. bassiana bersifat patogenik dan menyebabkan mortalitas kutu daun 78,8\% dan dapat menyebabkan mortalitas pada kepik hijau sebesar $76 \%$. Selain itu, dapat menggunakan ekstrak dari tumbuhan seperti ekstrak daun babadotan untuk dapat mengendalikan hama $N$. viridula. Taba et al. (2007), menyatakan bahwa ekstrak daun babadotan kering $90 \mathrm{~g} / \mathrm{l}$ efektif menekan intensitas serangan hama Kepik Hijau (Nezara viridula) dan Wereng Coklat (Nilaparvata lugens Stal) pada tanaman padi sebesar 12,96\% (57 HST) dan 15\% (67 HST).

Pengkombinasian antara agensia hayati dan pestisida nabari kini mulai banyak di kembangkan, misalnya penelitian Prayogo (2011), dalam penelitian tersebut diuji efikasi jamur entomopatogen Lecanicillium lecanii (Zimm.) yang dikombinasikan dengan insektisida nabati serbuk daun pacar cina Aglaia odorata, serbuk biji srikaya Annona squamosa, dan serbuk biji jarak Jatropha curcas. Hasil penelitian Prayogo (2011) menunjukkan bahwa kombinasi jamur entomopatogen 
dan pestisida nabati mampu meningkatkan mortalitas hama dalam pertanian. Berdasarkan pemikiran tersebut perlu juga dilakukan penelitian aplikasi B. Bassiana yang dikombinasikan dengan ekstrak daun babadotan. Diharapkan pengkombinasian bahan tersebut saat aplikasi dapat bersifat kompatibel dan dapat meningkatkan mortalitas hama $N$. viridula. Tujuan peneltian ini adalah untuk mengetahui pengaruh kompatibilitas jamur entomopatogen $B$. bassiana. dan pestisida nabati ekstrak daun babadotan terhadap nimfa instar 4 atau 5 kepik hijau (N. viridula) di laboratorium.

\section{BAHAN DAN METODE}

Penelitian ini dilaksanakan di Laboratorium Hama Fakultas Pertanian Universitas Lampung. Penelitian ini dimulai pada bulan Januari 2015 sampai dengan bulan Juli 2015. Penelitian ini terdiri dari 2 tahap, dimana tahap pertama disusun dalam Rancangan Acak Lengkap (RAL) dan tahap kedua disusun dalam Rancangan Acak Kelompok (RAK). Tahap pertama pengujian kompatiblitas jamur B. bassiana dan ekstrak daun babadotan menggunakan media PDA melalui penghtungan daya kecambah, pertumbuhan koloni, dan sporulasi dilakukan dengan 4 perlakuan dan 4 ulangan..

Tahap kedua adalah aplikasi kompatibilitas jamur B. bassiana dan ekstrak daun babadotan terhadap mortalitas hama $N$. viridula, sebanyak $1 \mathrm{ml}, 2 \mathrm{ml}, 3 \mathrm{ml}$ dilakukan dengan 6 perlakuan dan 4 ulangan. Data yang diperoleh diuji dengan analisis ragam dan dilanjutkan dengan uji BNT dengan taraf nyata 5\%. Biakan murni jamur diperoleh dari UPTD Balai Perlintanbun Tegineneng, Lampung. Jamur diperbanyak pada media Potato Dextrose Agar (PDA) dan media menir jagung yang diinkubasi selama \pm 2 minggu pada suhu ruang. Pada masing-masing ekstrak babadotan ditambahkan suspense $B$. bassiana $10 \mathrm{ml}$ dan perata perekat (Agristick) sebanyak 1ml/L.

Konidia dari hasil biakan tersebut dipanen menggunakan kuas atau spatula tanpa merusak media PDA, lalu dituang $5 \mathrm{ml}$ aquades. Setelah itu dilakukan pengenceran hingga mengandung $10^{7}$ konidia/ml suspensi konidia B. bassiana. Selanjutnya suspensi konidia diinkubasi pada kaca preparat dan diletakkan pada tissu lembab yang diletakkan pada nampan ditutup plastik wrap selama 24 jam. Kemudian perkecambahan konidianya diamati menggunakan mikroskop cahaya dengan perbesaran 400 kali. Persentase kecambah dihitung dari 100 konidia. Konidia dinyatakan berkecambah apabila panjang tabung kecambah telah melebihi diameter konidia. Penghitungan daya kecambah (viabilitas) spora dihitung dengan menggunakan rumus
Gabriel \& Riyanto (1989, dalam Herlinda et al., 2006) sebagai berikut:

$$
\mathrm{V}=\frac{\mathrm{g}}{\mathrm{g}+\mathrm{u}} \times 100 \%
$$

Keterangan:

$\mathrm{V}=$ perkecambahan konidia (viabilitas)

$\mathrm{g}=$ jumlah konidia yang berkecambah

$\mathrm{u}=$ jumlah konidia yang tidak berkecambah

Persentase penurunan daya kecambah konidia menurut Trizelia dan Rusli (2012) dihitung dengan rumus:

$$
\mathrm{Mr}=\frac{\mathrm{M} 2-\mathrm{M} 1}{\mathrm{M} 1} \times 100 \%
$$

Keterangan:

$\mathrm{Mr}=$ Persentase penurunan daya kecambah,

M1 = Daya kecambah konidia pada media yang tidak diberi ekstrak daun babadotan (kontrol)

M2 = Daya kecambah konidia pada media yang diberi ekstrak daun babadotan

Pertumbuhan koloni diukur secara acak pada 5 spot $B$. bassiana pada masing-masing perlakuan. Pengaruh ekstrak tersebut ditentukan dengan cara mengukur diameter koloni jamur setiap lima hari yang dimulai dari hari ke-5 sampai hari ke-15 setelah inokulasi. Diameter koloni dari cendawan diukur menggunakan penggaris. Persentase penurunan pertumbuhan koloni cendawan menurut Trizelia dan Rusli (2012) dihitung dengan rumus:

$$
\mathrm{Nr}=\frac{\mathrm{N} 1}{\mathrm{~N} 2} \times 100 \%
$$

Keterangan :

$\mathrm{Nr}=$ Persentase penurunan pertumbuhan koloni,

N1 = Pertumbuhan koloni jamur pada media yang tidak diberi ekstrak daun babadotan,

N2 = Pertumbuhan koloni jamur pada media yang diberi ekstrak daun babadotan

Sporulasi jamur B. bassiana ditentukan dengan menghitung jumlah spora yang dihasilkan jamur pada masing-masing perlakuan. Setelah inkubasi selama 15 hari pada cawan petri konidia jamur dipanen dengan cara menambahkan $5 \mathrm{ml}$ aquades, lalu dimasukkan ke dalam tabung reaksi. Selanjutnya suspensi tersebut dikocok menggunakan shaker dalam waktu 7 detik. Setelah selesai, diambil $1 \mathrm{ml}$ suspensi B. bassiana diletakkan pada haemocytometer. Haemocytometer ditutup cover glass, lalu diamati dan dihitung menggunakan mikroskop majemuk dengan perbesaran 
400 kali. Persentase penurunan sporulasi menurut Trizelia dan Rusli (2012) dihitung dengan rumus :

$$
\mathrm{Sr}=\frac{\mathrm{S} 1-\mathrm{S} 2}{\mathrm{~S} 1} \times 100 \%
$$

Keterangan:

$\mathrm{Sr}=$ Persentase penurunan sporulasi,

$\mathrm{S} 1=$ Jumlah spora yang dihasilkan jamur pada media yang tidak diberi ekstrak daun babadotan (kontrol),

S2= Jumlah spora yang dihasilkan jamur pada media yang diberi ekstrak daun babadotan

Untuk mengetahui pengaruh ekstrak daun babadotan terhadap jamur $B$. bassiana, maka data hasil pengamatan kompatibilitas dimasukkan ke dalam rumus T dari Alves et al. (1998, dalam Trizelia dan Rusli, 2012) sebagai berikut :

$$
\mathrm{T}=\frac{\{20(\mathrm{PK})+80(\mathrm{SP})\}}{100}
$$

Keterangan:

$\mathrm{T}=$ Nilai kompatibilitas,

$\mathrm{PK}=$ Nilai relatif pertumbuhan koloni perlakuan

dibandingkan dengan kontrol (\%),

$\mathrm{SP}=$ Nilai relatif sporulasi perlakuan dibandingkan dengan kontrol (\%).

Nilai T dibagi menjadi 4 kategori, yaitu 0-30 = sangat toksik; $31-45=$ toksik; $46-60=$ kurang toksik; dan $\mathrm{T}>60$ tidak toksik atau kompatibel.

Pengamatan dimulai dari 1 hari setelah aplikasi sampai 7 hari setelah aplikasi. Setiap satuan percobaan menggunakan serangga uji nimfa kepik hijau instar 4 atau 5 sebanyak 15 ekor, sehingga diperlukan 270 ekor nimfa. Aplikasi dilakukan 3 kali penyemprotan pada masing-masing perlakuan sebanyak $3 \mathrm{ml}$. Indikasi kematian dilakukan dengan cara mengamati serangga yang mati di bawah mikroskop, apakah pada tubuh serangga uji tumbuh cendawan $B$. bassiana. Persentase kematian serangga dihitung dengan rumus sebagai berikut (Rustama et al., 2008) :

$$
\begin{aligned}
& \qquad \mathrm{M}=\frac{\mathrm{n}}{\mathrm{N}} \times 100 \% \\
& \text { Keterangan: } \\
& \mathrm{M}=\text { mortalitas serangga }(\%) \\
& \mathrm{n}=\text { serangga yang mati (ekor) } \\
& \mathrm{N}=\text { jumlah serangga yang diuji }
\end{aligned}
$$

\section{HASIL DAN PEMBAHASAN}

Hasil penelitian menunjukkan bahwa konsentrasi babadotan berpengaruh nyata terhadap daya kecambah konidia B. bassiana $(\mathrm{P}<0,0001)$ terlihat pada Tabel 1 . Tabel 1 menunjukkan bahwa ekstrak daun babadotan secara nyata menghambat perkecambahan konidia jamur B. bassiana. Pada konsentrasi $1 \mathrm{ml}$ telah nyata menghambat perkecambahan konidia. Perkecambahan konidia $B$. bassiana menurun sampai 48,43\%. Pada konsentrasi $2 \mathrm{ml}$ daya kecambah konidia menurun $80,38 \%$ dan tidak berbeda nyata pada konsentrasi $3 \mathrm{ml}$ dengan penurunan daya kecambah konidia sampai $87,29 \%$. Berdasarkan hasil pada tabel tersebut, semakin tinggi konsentrasi ekstrak daun babadotan maka tingkat penghambatan terhadap perkecambahan konidia $B$. bassiana juga semakin tinggi. Hal ini terlihat pada penurunan daya kecambah konidia tersebut. Penurunan daya kecambah konidia sangat berpengaruh terhadap kemampuan jamur untuk menginfeksi serangga, karena perkecambahan konidia salah satu tahap penting dalam tahap infeksi tersebut dan paling menentukan dalam perkembangan penyakit pada serangga (Trizelia dan Rusli, 2012).

Selain berpengaruh terhadap daya kecambah konidia, konsentrasi ekstrak daun babadotan juga berpengaruh nyata terhadap pertumbuhan koloni jamur entomopatogen $B$. bassiana pada media PDA dibandingkan dengan kontrol. Semakin tinggi konsentrasi ektrak daun babadotan maka pertumbuhan koloni jamur semakin terhambat, seperti yang tertera pada Tabel 2 . Hasil percobaan menunjukkan bahwa penambahan konsentrasi ekstrak babadotan pada media PDA mampu menghambat pertumbuhan koloni jamur $B$. bassiana. Pada perlakuan K2 dan K3 dengan penambahan $2 \mathrm{ml}$ dan $3 \mathrm{ml}$ ekstrak babadotan menunjukkan bahwa pertumbuhan koloni B. bassiana pada hari ke 15 hanya sebesar 1,95 dan $1,86 \mathrm{~cm}$, yang berarti mengalami penurunan pertumbuhan koloni jamur B. bassiana antara 34,40-41,90\%. Trizelia dan Rusli (2012) juga menyatakan bahwa minyak serai wangi yang ditambahkan pada media PDA secara nyata menghambat pertumbuhan koloni jamur entomopatogen B. bassiana. Pada konsentrasi 0,3 dan 0,5\%, jamur tidak mampu berkembang. Tingkat penurunan pertumbuhan koloni jamur sekitar 36,73-90,30\% . Tingkat penghambatan sangat dipengaruhi oleh konsentrasi penambahan ekstrak nabati.

Pada Tabel 2 juga terlihat bahwa pemberian ekstrak daun babadotan menurunkan kemampuan jamur dalam bersporulasi secara nyata dibandingkan dengan kontrol. Pada perlakuan P1 penambahan $1 \mathrm{ml}$ ekstrak daun babadotan secara nyata menghambat $B$. bassiana bersporulasi dengan penurunan sebesar 49,34\%. Bahkan pada perlakuan $\mathrm{P} 3$ penambahan $3 \mathrm{ml}$ ekstrak daun babadotan, B. bassiana bersporulasi hanya 
Tabel 1. Pengaruh pemberian ekstrak daun babadotan terhadap daya kecambah konidia B. bassiana setelah inkubasi selama 24 jam.

\begin{tabular}{ccccccc}
\hline \multirow{2}{*}{$\begin{array}{c}\text { Perlakuan konsentrasi } \\
\text { ekstrak daun babadotan }\end{array}$} & \multicolumn{7}{c}{ Diameter koloni (cm) } \\
\cline { 2 - 7 } & $5 \mathrm{hsa}$ & \% penurunan & $10 \mathrm{hsa}$ & $\%$ penurunan & $15 \mathrm{hsa}$ & \% penurunan \\
\hline K0 $(0 \mathrm{ml} / 10 \mathrm{ml}$ PDA) & $0,66 \mathrm{a}$ & 0 & $1,36 \mathrm{a}$ & 0 & $3,20 \mathrm{a}$ & 0 \\
$\mathrm{~K} 1(1 \mathrm{ml} / 10 \mathrm{ml}$ PDA) & $0,40 \mathrm{~b}$ & 38,93 & $0,97 \mathrm{~b}$ & 29,04 & $2,10 \mathrm{~b}$ & 34,40 \\
$\mathrm{~K} 2(2 \mathrm{ml} / 10 \mathrm{ml}$ PDA $)$ & $0,41 \mathrm{~b}$ & 38,17 & $0,88 \mathrm{~b}$ & 35,66 & $1,95 \mathrm{~b}$ & 39,24 \\
$\mathrm{~K} 3(3 \mathrm{ml} / 10 \mathrm{ml}$ PDA) & $0,43 \mathrm{~b}$ & 35,11 & $0,88 \mathrm{~b}$ & 35,29 & $1,86 \mathrm{~b}$ & 41,90 \\
\hline Pr $<$ F & 0,0104 & - & 0,0001 & - & 0,0001 & - \\
\hline BNT 0,05 & 0,156 & & 0,136 & & 0,4391 & - \\
\hline
\end{tabular}

Keterangan: $\operatorname{Pr}<\mathrm{F} 0,1=$ sangat nyata. Nilai sekolom yang diikuti huruf yang sama berarti tidak berbeda nyata pada Uji BNT taraf nyata $5 \%$.

Tabel 2. Pengaruh pemberian ekstrak daun babadotan pada media PDA terhadap pertumbuhan koloni B. bassiana dan sporulasi B. bassiana setelah inkubasi selama 15 hari.

\begin{tabular}{lcccc}
\hline $\begin{array}{c}\text { Perlakuan konsentrasi ekstrak } \\
\text { daun babadotan }\end{array}$ & $\begin{array}{c}\text { Daya } \\
\text { kecambah } \\
\text { konidia }(\%)\end{array}$ & $\begin{array}{c}\text { Persentase penurunan } \\
\text { daya kecambah } \\
\text { konidia }(\%)\end{array}$ & $\begin{array}{c}\text { Jumlah } \\
\text { konidia } \\
\left(\mathrm{x} 10^{7} / \mathrm{ml}\right)\end{array}$ & $\begin{array}{c}\text { Persentase } \\
\text { penurunan Jumlah } \\
\text { konidia }(\%)\end{array}$ \\
\hline D0 (Kontrol 0 ml/10 ml PDA) & $47,32 \mathrm{a}$ & 0,00 & $39,15 \mathrm{a}$ & 0 \\
D1 (1 ml/10 ml PDA) & $24,40 \mathrm{~b}$ & 48,43 & $19,83 \mathrm{~b}$ & 49,34 \\
D2 $(2 \mathrm{ml} / 10 \mathrm{ml}$ PDA) & $9,28 \mathrm{c}$ & 80,38 & $9,98 \mathrm{c}$ & 74,50 \\
D3 (3 ml/10 ml PDA) & $6,02 \mathrm{c}$ & 87,29 & $6,35 \mathrm{~d}$ & 83,78 \\
\hline Pr < F & 0,0001 & - & 0,0001 & - \\
\hline BNT 0,05 & 8,60 & - & 1,1551 & - \\
\hline
\end{tabular}

Keterangan: Pr $<$ F 0,1 = sangat nyata. Nilai sekolom yang diikuti huruf yang sama berarti tidak berbeda nyata pada Uji BNT taraf nyata $5 \%$.

mencapai $6,35 \%$ dan presentase penurunan bersporulasi mencapai $83,78 \%$. Penurunan kemampuan jamur bersporulasi juga dilaporkan oleh Trizelia dan Rusli (2012) yang mengemukakan bahwa kemampuan jamur untuk membentuk konidia mempunyai arti penting yaitu apabila sporulasi yang dihasilkan sedikit maka pemencaran (pertumbuhan) jamur terbatas dan kemampuannya sebagai agensia hayati juga berkurang.

Selanjutnya menurut Depieri et al. (2005, dalam Trizelia dan Rusli, 2012), penurunan jumlah konidia $B$. bassiana yang ditambahkan ekstrak nimba dalam bentuk emulsi berpengaruh secara nyata berkisar antara 49,8-78,7\%. Perlakuan dalam bentuk ekstrak air daun dan biji nimba tidak berpengaruh nyata terhadap jumlah konidia dan tingkat penurunannya berkisar antara 0,5 $41,5 \%$, bergantung pada konsentrasi ekstrak. Semakin tinggi tingkat sporulasi berarti semakin besar kemampuan jamur entomopatogen menginfeksi (Trizelia, 2005 dalam Mardiana et al., 2015).

Berdasarkan nilai T, klasifikasi kompatibilitas ekstrak daun babadotan dengan jamur entomopatogen
B. bassiana dapat dilihat pada Tabel 3. Tabel 3 menunjukkan bahwa perlakuan dengan ekstrak daun babadotan pada perlakuan $1 \mathrm{ml}$ menunjukkan nilai pada peringkat kurang toksik terhadap jamur B. bassiana dan apabila ditingkatkan jumlah penambahan ekstrak daun babadotan hingga $3 \mathrm{ml}$ bersifat sangat toksik yang artinya tidak kompatibel terhadap jamur B. bassiana. Nilai kompatibilitas ini menunjukkan bahwa ekstrak daun babadotan dan B. bassiana tidak kompatibel dan didukung oleh data penurunan daya kecambah konidia, pertumbuhan koloni dan sporulasi jamur B. bassiana

Tabel 3. Klasifikasi kompatibilitas ekstrak babadotan dengan jamur entomopatogen B. bassiana.

\begin{tabular}{ccc}
\hline Perlakuan & $\mathrm{T}$ & Tingkat kompatibilitas* \\
\hline $1 \mathrm{ml}$ & 54,52 & kurang toksik \\
$2 \mathrm{ml}$ & 33,22 & toksik \\
$3 \mathrm{ml}$ & 25,91 & sangat toksik \\
\hline
\end{tabular}

* klasifikasi menurut Alves et al. (1998, dalam Trizelia dan Rusli, 2012) 
secara nyata. Oleh karena itu penggunaan ekstrak babadotan yang tidak kompatibel dengan jamur entomopatogen $B$. bassiana tidak disarankan untuk diaplikasikan secara bersamaan. Setelah melihat hasil dari pertumbuhan koloni dan sporulasi, dapat diketahui bahwa penambahan ekstrak daun babadotan sangat berpengaruh nyata terhadap pertumbuhan jamur $B$. bassiana. Ekstrak kasar $A$. conyzoides mengandung dua komponen biologis yang bersifat aktif menekan perkembangan serangga, diantaranya yaitu precocene I dan precocene II. Sedangkan Ageratochromenes (precocene II) dari ekstrak A.conyzoides bagian pucuk daun memiliki fungsi sebagai antijamur. Menurut Iqbal et al. (2004 dalam Adebayo et al., 2010) bahwa precocene II dapat menghambat pertumbuhan dua spesies jamur yaitu jamur Rhizoctonia solani dan Sclerotium rolfsii. Berdasarkan penelitian tersebut diduga ekstrak daun babadotan (A. conyzoides) berperan sebagai fungisida.

Tabel 4 menunjukkan bahwa aplikasi tunggal suspensi $B$. bassiana $10^{7}$ konidia spora/ml (H5) menyebabkan mortalitas N. viridula sebesar $73 \%$. Aplikasi tunggal pestisida nabati ekstrak daun babadotan (H6) menyebabkan mortalitas N. viridula sebesar 91\%, dimana nilai tersebut tidak berbeda nyata dengan perlakuan H5. Mortalitas N. viridula pada perlakuan aplikasi suspensi $B$. bassiana $10 \mathrm{ml}$ ditambahkan ekstrak daun babadotan $1 \mathrm{ml}(\mathrm{H} 2)$ sebesar $47 \%$ dan berbeda

Tabel 4. Mortalitas N.viridula 7 hari setelah aplikasi

\begin{tabular}{|c|c|}
\hline Perlakuan & $\begin{array}{c}\text { Mortalitas } \\
\text { N. viridula (\%) }\end{array}$ \\
\hline H1 (Kontrol) & $0,00 \mathrm{~d}$ \\
\hline $\begin{array}{c}\text { H2 (Suspensi B. bassiana } 10 \\
\text { ml ditambahkan ekstrak } \\
\text { daun babadotan } 1 \mathrm{ml} \text { ) }\end{array}$ & $47 \mathrm{c}$ \\
\hline $\begin{array}{l}\text { H3 Suspensi B. bassiana } 10 \\
\text { ml ditambahkan ekstrak } \\
\text { daun babadotan } 2 \mathrm{ml} \text { ) }\end{array}$ & $64 \mathrm{bc}$ \\
\hline $\begin{array}{c}\text { H4 Suspensi B. bassiana } 10 \\
\text { ml ditambahkan ekstrak } \\
\text { daun babadotan } 3 \mathrm{ml} \text { ) }\end{array}$ & $60 \mathrm{bc}$ \\
\hline $\begin{array}{l}\text { H5 (Suspensi B. bassiana } 10^{7} \\
\text { konidia spora/ ml) }\end{array}$ & $73 \mathrm{ab}$ \\
\hline H6 (Ekstrak daun babadotan) & $91 \mathrm{a}$ \\
\hline $\operatorname{Pr}<F$ & 0,0001 \\
\hline BNT 0,05 & 19,119 \\
\hline
\end{tabular}

Keterangan: $\operatorname{Pr}<$ F 0,1 = sangat nyata. Nilai sekolom yang diikuti huruf yang sama berarti tidak berbeda nyata pada Uji BNT taraf nyata $5 \%$. nyata dengan mortalitas $N$. viridula pada perlakuan $\mathrm{H} 5$ dan H6. Namun perlakuan aplikasi suspensi B. bassiana $10 \mathrm{ml}$ ditambahkan ekstrak daun babadotan $2 \mathrm{ml}(\mathrm{H} 3)$ sebesar $64 \%$ dan berbeda nyata dengan mortalitas $N$. viridula pada perlakuan $\mathrm{H} 2$, tetapi tidak berbeda nyata dengan mortalitas $N$. viridula pada perlakuan H5 dan aplikasi suspensi B. bassiana $10 \mathrm{ml}$ ditambahkan ekstrak daun babadotan $3 \mathrm{ml}$ (H4) sebesar 60\%.

Menurut Iqbal et al. (2004, dalam Adebayo et al., 2010) menyatakan bahwa Ageratochromenes (precocene II) dari ekstrak A.conyzoides bagian pucuk daun memiliki fungsi sebagai antijamur. Oleh karena itu, penambahan ekstrak daun babadotan pada formulasi jamur $B$. bassiana dapat menekan jumlah konidia jamur dalam menginfeksi hama $N$. viridula. Semakin besar konsentrasi penambahan ekstrak daun babadotan maka semakin kecil kuantitas dan kualitas konidia serta semakin kecil tingkat mortalitas hama. Menurut Hasnah et al. (2012) perbedaan persentase kematian nimfa yang terinfeksi jamur B. bassiana terjadi karena perbedaan kuantitas konidia yang diaplikasikan pada masing-masing perlakuan.

\section{KESIMPULAN}

Berdasarkan penelitian yang telah dilaksanakan dapat disimpulkan bahwa hasil uji kompatibilitas cendawan entomopatogen $B$. bassiana dengan pestisida nabati ekstrak daun babadotan tidak kompatibel. Hasil uji menunjukkan bahwa ekstrak daun babadotan menghambat daya kecambah konidia, pertumbuhan koloni, dan sporulasi. Tingkat penghambatan bervariasi bergantung pada jumlah penambahan ekstrak daun babadotan. Aplikasi tunggal B. bassiana menyebabkan mortalitas $N$. viridula sebesar $73 \%$ dan aplikasi tunggal ekstrak daun babadotan menyebabkan mortalitas $N$. viridula sebesar $91 \%$. Aplikasi tunggal suspensi $B$. bassiana dan aplikasi tunggal ekstrak daun babadotan menyebabkan mortalitas $N$. viridula yang lebih tinggi dibandingkan mortalitas $N$. viridula pada aplikasi penambahan ekstrak daun babadotan.

\section{DAFTAR PUSTAKA}

Adebayo, A.H., G.Z. Zeng, Y. M. Zang, C. J. Ji, A. A. Akindahunsi dan N. H. Tan. Toxicological evaluation of precocene II isolated from Ageratum conyzoides L. (Asteraceae) in sprague dawley rat. African Journal of Biotecnology 9(20) : 2938-2944

Hasnah, Susanna, dan H. Sably. 2012. Keefektifan cendawan Beauveria bassiana Vuill terhadap 
mortalitas kepik hijau Nezara viridula L. pada stadia nimfa dan imago. J. Floratek 7 : 13-24.

Herlinda, S., M. D. Utama, Y. Pujiastuti, dan Suwandi. 2006. Kerapatan dan viabilitas spora Beauveria bassiana (Bals.) Vuill. akibat subkultur dan pengayaan media, serta virulensinya terhadap larva Plutella xylostella (Linn.). J. HPT Tropika 6(2):70-78.

Indriyati. 2009. Virulensi jamur entomopatogen Beauveria bassiana (Balsamo) Vuillemin (Deutromycotina : hyphpmycetes) terhadap kutudaun (Aphis spp.) dan kepik hijau (Nezara viridula). J. HPT Tropika 9(2): 92-98.

Mardiana, Y., D. Salbiah, dan L.J. Hennie. 2015. Penggunaan beberapa konsentrasi Beauveria bassiana Vuillemin lokal untuk mengendalikan Maruca testulalis Geyer pada tanaman kacang panjang (Vigna sinensis L.). JOM Faperta Universitas Riau 2(1): 1-11.

Prayogo, Y. 2011. Sinergisme cendawan entomopatogen Lecanicillium lecanii dengan insektisida nabati untuk meningkatkan efikasi pengendalian telur kepik coklat Riptortus linearis pada kedelai. $J$. HPT Tropika 11(2): 166-177.
Prayogo, Y. 2012. Efikasi cendawan entomopatogen Beauveria bassiana (Bals.) Vuill. (Deuteromycotina: Hyphomycetes) terhadap kepik hijau (Nezara virdula L.). J. HPT Tropika 2(1): 1-14.

Rustama, M., M. Melanie dan B. Irawan. 2008. Patogenisitas jamur entomopatogen Metarhizium anisopliae terhadap Crocidolomia pavonana Fab. dalam kegiatan studi pengendalian hama terpadu tanaman kubis dengan menggunakan agensia hayati. Laporan Akhir Penelitian Peneliti Muda. Universitas Padjadjaran. $58 \mathrm{hlm}$

Taba, A.H., M.Y. Surung, dan I.N.R. Parawansa. 2007. Evaluasi penyuluhan dan analisis usahatani penggunaan pestisida nabati babadotan (Ageratum conyzoides) pada hama wereng coklat (Nilaparvata lugens Stal). J.Agrisistem 3(2) : 95-101.

Trizelia dan R. Rusli. 2012. Kompatibilitas cendawan entomopatogen Beauveria bassiana (bals) Vuill (Deuteromycotina: Hyphomycetes) dengan minyak serai wangi. J.HPT Tropika 12(1): 7884. 